\title{
Uma Revisão Sistemática de Comportamentos Pré-Linguísticos e Primeiros Comportamentos Linguísticos em Crianças Cegas CONGÊNITAS ${ }^{1}$
}

\author{
A Systematic REVIEW of Pre-Linguistic and EARLy Linguistic BeHaViors in \\ CHILDREN With CONGENITAL BLINDNESS
}

\author{
Ana Carolina SELLA ${ }^{2}$ \\ Taís CHIODELLI ${ }^{3}$ \\ Camila de Almeida MENDES ${ }^{4}$
}

\begin{abstract}
RESUMO: a ausência do desenvolvimento da linguagem pode resultar em diversos problemas. Uma população a qual pode ser bastante afetada por déficits de linguagem é a população nascida cega. O objetivo desta revisão sistemática da literatura foi compilar estudos empíricos que tiveram por alvo descrever e/ou avaliar o desenvolvimento de comportamentos pré-linguísticos e linguísticos iniciais em crianças cegas congênitas. Foram encontrados 19 estudos que possuíam todos os critérios definidos para esta revisão bibliográfica. Os 19 estudos foram analisados em relação: a) a quais bases de dados e periódicos publicaram e arquivam tais artigos; b) ao número de estudos envolvendo: primeiras palavras, alcançar e buscar objetos, atenção conjunta, e outros comportamentos linguísticos; à presença ou ausência de definiçôes operacionais dos comportamentos-alvo; d) aos objetivos dos estudos. Os estudos foram publicados em 11 periódicos diferentes. A maior parte dos estudos tinha como foco as primeiras palavras dos participantes. Em relação às definiçóes operacionais, 15 estudos possuíam alguma informação acerca de tal definição. $\mathrm{O}$ presente artigo sintetiza diversos estudos que abordam o desenvolvimento da linguagem em crianças cegas congênitas e pode ser utilizado como um guia para pesquisas futuras na área.
\end{abstract}

PALAVRAS-CHAVE: Educação Especial. Cego. Linguagem.

\begin{abstract}
The absence of language development may result in several problems. People with congenital blindness are among those who could be highly affected by language deficits. The purpose of this systematic literature review was to compile empirical studies that aimed at describing and/or assessing the development of pre-linguistic and early linguistic behaviors in children with congenital blindness. Among the studies that were found, 19 met the criteria defined for this literature review. All 19 studies were analyzed in regards to: (a) which data bases and journals published or archived these studies; (b) the number of studies that targeted either: early words, reach and search for objects, joint attention, or other linguistic behaviors; (c) the presence or absence of operational definitions for the target behaviors; (d) the studies' purposes. The studies were published by 11 different journals. The majority of the studies focused on early words as target behaviors. In regards to operational definitions, 15 studies provided some information concerning these definitions. This paper synthesizes several studies that address language development of congenitally blind children and could be used as a guide for future research in congenital blindness.
\end{abstract}

KEYWORDS: Special Education. Blindness. Language.

\section{InTROdUÇÁo}

A importância da linguagem pode ser reconhecida em todas as esferas humanas na atualidade. Conforme descrito por Skinner (1992), Sundberg (2007), entre outros, comportamentos verbais estão envolvidos no interagir socialmente, no resolver problemas, no pensar, na ciência, na política, entre diversos outros contextos. Em relação a sua evolução e

${ }^{1}$ Agradecimentos: Agradecemos a Gustavo Wolff Cardoso, Silviane Krokosz, Suzana S. Souza, Ana Carla Penzo e Young Sam Otávio pela colaboração na fase inicial da pesquisa.

${ }^{2}$ Doutora em Educaçáo Especial, Universidade Federal da Grande Dourados. carolsella@yahoo.com.br

${ }^{3}$ Acadêmica de Psicologia, Universidade Federal da Grande Dourados, Dourados, Mato Grosso do Sul. tais.chiodelli@hotmail.com

${ }^{4}$ Acadêmica de Psicologia, Universidade Federal da Grande Dourados, Dourados, Mato Grosso do Sul. cah_mendes@hotmail.com 
manutenção ao longo da história da espécie humana, conforme ressaltado por Bandini (2008) e Skinner (1992), o comportamento verbal provavelmente aumentou a chance de sobrevivência de grupos sociais humanos e foi selecionado ao longo das diversas geraçóes: respostas verbais transmitidas a outros seres humanos possibilitaram a transportabilidade de informação. Desta forma, tornou-se possível responder a eventos ambientais sem a necessidade de contato direto com as consequências de diversos comportamentos.

A ausência do desenvolvimento da linguagem pode resultar em diversos problemas que incluem déficits de habilidades sociais (FUJIKI; BRINTON; TODD, 1996), agressão (QI; KAISER, 2004), analfabetismo (BOUDREAU; HEDBERG, 1999), entre outros. Por isso, a prevenção e remediação de déficits de linguagem tem recebido atenção especial de diversas áreas do conhecimento (BUSCHMANN et al., 2009; GILLAM et al., 2008; WARREN; FEY; YODER, 2007).

Uma população a qual pode ser bastante afetada por déficits de linguagem é a população nascida cega. Segundo Silver (2003), cerca de 80 a $90 \%$ da aprendizagem infantil é baseada em informações visuais. Autores como Andersen, Dunlea, e Kekelis (1993), Bigelow (2003), Moore e McConachie (1994), Preisler (1991) e Urwin (1979) ressaltam que tanto as formas de comunicação pré-verbais, como as verbais são dominadas por experiências visuais e incluem buscar e alcançar objetos, usar gestos, atenção conjunta, imitação (tanto vocal como não vocal) e as primeiras palavras da criança. Portanto, a falta de visão pode acarretar déficits no desenvolvimento de todos estes comportamentos os quais culminam com o desenvolvimento da linguagem fluente (BIGELOW, 1986, 2003; IVERSON et al., 2000).

Apesar da escassez de estudos acerca do desenvolvimento da linguagem - especialmente a linguagem infantil - nesta população, é possível encontrar algumas pesquisas que abordam esta questão. Todavia, os dados até agora obtidos divergem em alguns pontos importantes. Por exemplo, autores como Andersen, Dunlea e Kekelis (1984), Iverson et al. (2000) e Mills (1993) argumentam que crianças cegas não possuem atrasos significativos em seu desenvolvimento quando este é comparado àquele de crianças com visão, apesar de as crianças cegas alcançarem diferentes estágios do desenvolvimento em idades distintas daquelas esperadas para crianças com visão. Segundo esses autores, as diferenças advêm das experiências idiossincráticas que crianças cegas têm com seu ambiente, portanto não podem ser caracterizadas como atrasos. Outros autores, como Fraiberg (1971, 1977), afirmam que há atrasos significativos no desenvolvimento de crianças cegas e sugerem que programas de intervenção precoce sejam criados, assim que possível, para prevenir déficits ainda mais severos do que aqueles comumente encontrados nesta população.

Além da divergência encontrada em relação a possíveis atrasos do desenvolvimento da linguagem em crianças cegas, os autores e pesquisadores que tratam do desenvolvimento destes comportamentos adotam diversos referenciais teóricos. Esta diversidade de referenciais teóricos acaba se refletindo na metodologia das pesquisas e na interpretação dos dados obtidos: comportamentos similares são descritos e avaliados de forma diferente. Além disso, é possível que dados similares sejam interpretados de forma diferente: o que é considerado normal por um pesquisador, pode ser interpretado como atraso sob outro referencial. De tal diversidade resulta que pessoas buscando formas de avaliar (e intervir com) comportamentos linguísticos 
nesta população, acabam não encontrando consenso entre os estudos e, como consequência, decisôes acerca do curso de avaliaçóes e intervençóes podem demorar longos períodos de tempo e cabam por serem cercadas de incertezas. Uma revisão da literatura que busque similaridades entre os estudos já realizados na área poderia auxiliar em tal busca por informaçóes.

\section{A DEFINIÇÃO DE LINGUAGEM NO PRESENTE ESTUDO}

Tendo em vista a miríade de significados e conotaçóes que a palavra linguagem pode receber nas mais diversas áreas do conhecimento e devido aos diversos referenciais teóricos utilizados para estudá-la, o presente estudo buscou, primeiramente, estabelecer o que seria inserido dentro do conjunto de comportamentos denominado linguagem.

A princípio, pensou-se em utilizar uma perspectiva inteiramente analíticocomportamental, inclusive substituindo o termo linguagem por comportamento verbal. Dentro dessa abordagem, para uma resposta ser considerada verbal é necessária a presença de um falante e de um ouvinte (mesmo que estes sejam a mesma pessoa). Além disso, o ouvinte deve ser o mediador das consequências para o comportamento do falante e deve ter sido especialmente condicionado para realizar tal mediação. Além disso, quando analisados comportamentos verbais, a função do comportamento deve ser especificada em termos de antecedentes, respostas e consequências.

Uma revisão bibliográfica inicial, a qual utilizou como palavras-chave cego, cegueira, deficiência visual, juntamente com a palavra linguagem, resultou em estudos cujo foco estava na topografia de comportamentos. Isto significa que a forma (ou estrutura) das respostas era especificada. No entanto, os antecedentes e as consequências de tais respostas não estavam necessariamente definidos nos estudos. Esta forma recorrente de olhar para comportamentos pré-linguísticos e primeiros comportamentos linguísticos em termos de topografia, culminou na decisão de sequer utilizar o termo comportamento verbal (o qual reflete a função do comportamento). Comportamentos pré-linguísticos e primeiros comportamentos linguísticos (os quais refletem a topografia do comportamento) passaram a ser o foco da busca bibliográfica e posteriores análises e discussão.

Após esta mudança, novas palavras-chave foram cunhadas para a revisão bibliográfica. Tais palavras-chave foram retiradas de categorias presentes em escalas e artigos científicos que costumam ser utilizados como base para a avaliação de comportamentos linguísticos em populaçóes com os mais diversos tipos de deficiências severas como, por exemplo, The Triple C: Checklist of Communication Competencies - Revised (BLOOMBERG; WEST, 1999) e a Online Communication Matrix (ROWLAND, 2009).

O objetivo da presente revisão de literatura foi compilar estudos empíricos conduzidos de 1985 a 2011 que tiveram por alvo descrever e/ou avaliar o desenvolvimento de comportamentos pré-linguísticos e linguísticos iniciais em crianças cegas congênitas. A partir desta compilação, avaliaram-se (a) quais têm sido os principais comportamentos-alvo destes estudos (topografias de respostas) e (b) quais estudos fornecem definiçóes operacionais dos chamados comportamentos pré-linguísticos e linguísticos (descrições detalhadas acerca da topografia dos comportamentos-alvo). 


\section{Desenvolvimento}

O presente artigo é derivado de uma revisão bibliográfica sistematizada acerca do desenvolvimento de comportamentos pré-linguísticos e linguísticos iniciais em crianças cegas congênitas. Conforme descrito anteriormente, esta revisão possuiu em dois momentos. No primeiro, quando a funçáo do comportamento seria o foco da pesquisa, as palavras-chaves cego, cegueira e deficiência visual foram utilizadas em conjunto com a palavra linguagem. As bases de dados pesquisadas foram Google Acadêmico, PubMed, Psycinfo e Scielo. No segundo momento, quando a topografia do comportamento passou a ser o alvo da revisão, novos critérios e palavras-chaves foram cunhados. Este segundo momento é o foco do presente manuscrito e uma descrição detalhada de tal busca, seus critérios e seus resultados são apresentados a seguir.

Em relação às palavras-chaves, foram cruzadas as palavras: cego, deficiente visual, cegueira ou deficiência visual com as palavras alcançar objetos, primeiras palavras, atenção conjunta ou buscar objetos. Estas palavras também foram buscadas em inglês: blind, people with visual disabilities, blindness ou visual disability cruzadas com object reach, early words, joint attention and object search. Isto significa que para cada base de dados pesquisada houve, no mínimo, a busca por 32 combinações de palavras (por exemplo, blind juntamente com object reach e, a seguir, blind juntamente com early words).

Foram utilizados cinco critérios como filtros para os estudos encontrados. O primeiro critério foi que as crianças fossem cegas congênitas, pois a literatura aponta que crianças que não são completamente cegas ou que ficaram cegas após terem adquirido comportamentos linguísticos, não são tão negativamente afetadas pela cegueira em relação ao desenvolvimento da linguagem. O segundo critério foi que apenas estudos entre 1985 e 2011 fossem considerados. O terceiro critério foi relativo à idade das crianças: como comportamentos pré-linguísticos e primeiros comportamentos linguísticos foram o foco da pesquisa, apenas estudos cujos participantes tinham entre 0 e 6 anos (primeira infância) foram considerados. $\mathrm{O}$ quarto critério foi que o estudo fosse empírico e que os experimentadores tivessem observado e registrado comportamentos das crianças. Estudos que envolviam familiares e/ou professores, e que não descreviam comportamentos das crianças em si, foram considerados fora deste critério. $\mathrm{O}$ quinto critério se referiu à deficiência das crianças. Pelo menos um grupo de participantes deveria conter crianças cuja única deficiência fosse visual, pois é sabido que outras deficiências associadas resultam em outros déficits, os quais interferem de forma diferente no desenvolvimento infantil.

Após a realização da busca de palavras-chaves, os resumos de cada estudo foram lidos para julgar sua relevância para a busca. Se o resumo fornecesse informaçóes de que os critérios não estariam presentes no artigo, o artigo era descartado (por exemplo, se o resumo dissesse que os participantes eram adultos cegos congênitos). A seguir, os artigos não descartados foram lidos e os critérios acima descritos foram aplicados aos estudos encontrados. Com os artigos que restaram após a seleção baseada nos critérios, as seguintes informações foram extraídas e analisadas: 1) autor, ano e título do artigo; 2) periódico, volume, número e páginas; 3) palavras-chave citadas pelo estudo; 4) objetivo(s) do estudo; 5) participantes do estudo; 6) comportamentos-alvo; 7) se houve definição operacional dos comportamentos pré-linguísticos e/ou primeiros comportamentos linguísticos; 8) se houve definição operacional, qual foi a descrição da mesma; 9) base(s) de dados na qual o artigo foi encontrado. 
Mais especificamente, as variáveis dependentes de interesse na presente revisão bibliográfica foram: 1) número de estudos que possuíam todos os critérios acima definidos (tanto na literatura internacional, quanto na literatura nacional); 2) Periódicos e bases de dados nas quais os estudos foram encontrados; 3) Principais comportamentos-alvo dos estudos; e 4) a presença de definiçáo operacional de comportamentos pré-linguísticos e linguísticos.

As informações extraídas dos estudos possibilitaram não apenas a análise de cada uma destas variáveis dependentes, mas também a elaboração de resumos descritivos que incluíam informaçóes específicas sobre tais variáveis em cada um dos estudos, assim como seus objetivos e participantes.

\section{Resultados Da BUSCA}

Os resultados, apresentados a seguir, foram descritos em relação: 1) ao número de estudos encontrados que possuíam os critérios acima descritos; 2) as bases de dados e periódicos nos quais tais artigos foram encontrados; 3) o número de estudos encontrados para cada comportamento-alvo utilizado como palavra-chave; 4) a frequência de estudos com e sem presença de definiçóes operacionais dos comportamentos-alvo; e 5) aos objetivos e comportamentosalvo dos estudos. A descrição dos estudos contendo objetivos e comportamentos-alvo foi dividida de acordo com a presença ou ausência de definiçóes operacionais. Dados acerca dos participantes dos estudos encontram-se nos Quadros 1 e 2 e não foram duplicados na descrição dos resultados.

Foram encontrados 19 estudos que possuíam todos os critérios definidos para esta revisão bibliográfica. Dentre estes estudos, 15 foram publicados internacionalmente e quatro, nacionalmente. Alguns dos artigos foram encontrados em mais de uma das bases de dados. Por isso, a soma do número de estudos encontrados em cada base de dados resulta em mais do que 19 estudos. O Google Acadêmico foi a base de dados que resultou no maior número de artigos que possuíam todos os critérios (13 estudos). A base Psycinfo resultou em 11 artigos e a base Pubmed, em cinco artigos. A base de dados Scielo não resultou em artigos que possuíssem todos os critérios. Os periódicos internacionais nos quais os artigos foram publicados foram Brain and Development, British Journal of Developmental Psychology, Child: Care, Health and Development, Development and Psychopathology, Developmental Medicine \& Child Neurology, Early Human Development, Infant Behavior and Development, Journal of Applied Developmental Psychology, Journal of Child Language, Journal of Visual Impairment \& Blindness e Text - Interdisciplinary Journal for the Study of Discourse. Os periódicos nacionais foram Estudos de Psicologia e Temas em Psicologia. Ainda foram encontradas duas dissertaçóes de mestrado brasileiras: uma da Universidade Federal da Bahia e uma da Universidade Federal da Paraíba.

A Figura 1 mostra o número de estudos encontrados por comportamentos-alvo utilizado como palavra-chave. Os comportamentos relacionados à coordenaçáo motora (alcançar objetos; buscar objetos) foram agrupados em uma categoria única por haver diversos estudos que avaliaram os dois comportamentos. Oito estudos tiveram primeiras palavras como comportamentos-alvo. Cinco estudos tiveram alcançar objetos e/ou buscar objetos como comportamentos-alvo. Um estudo focou-se na atenção conjunta e cinco estudos incluíram comportamentos relacionados às palavras-chave, mas que se focaram primariamente em 
outros comportamentos-alvo. Por exemplo, Campbell (2003) analisou comportamentos comunicativos iniciados pela mãe e as interaçóes comunicativas entre mãe e bebê, portanto os comportamentos-alvo deste estudo se relacionavam, mas não eram exatamente os comportamentos-alvo englobados pela presente pesquisa.

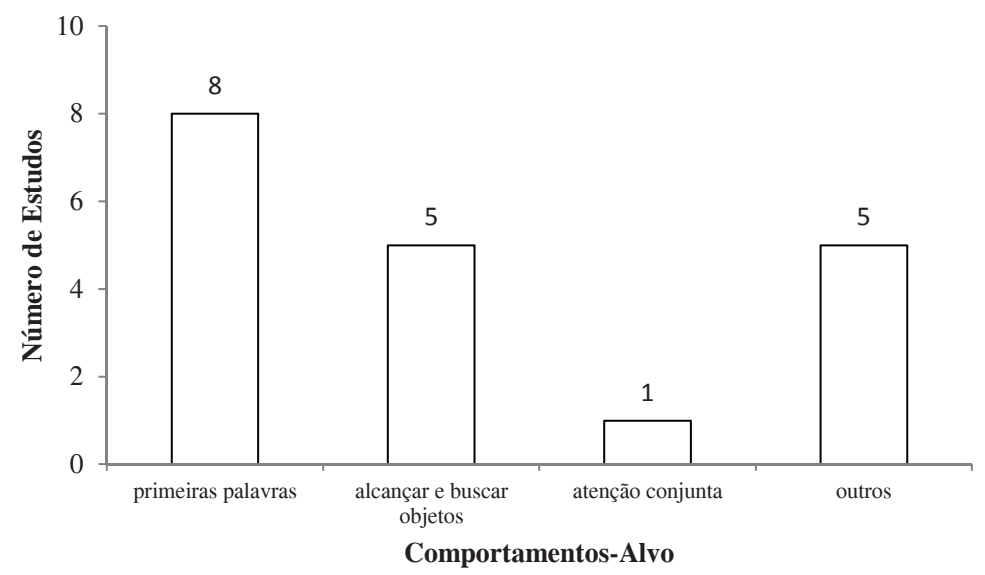

Figura 1 - Número de estudos encontrados para cada comportamento utilizado como palavrachave.

Fonte: própria do autor

A Tabela 1 mostra a frequência relativa e a frequência absoluta de estudos com e sem presença de definiçóes operacionais dos comportamentos-alvo. Quinze estudos possuíam alguma definição operacional dos comportamentos-alvo, enquanto quatro não apresentaram tal definição.

Tabela 1 - Frequências absoluta e relativa da presença de definição operacional.

\begin{tabular}{lcc}
\hline Presença de definição operacional & Frequência absoluta (n) & Frequência relativa (\%) \\
\hline Sim & 15 & $78.9 \%$ \\
Não & 4 & $21.1 \%$ \\
\hline Total & 19 & $100.0 \%$ \\
\hline
\end{tabular}

Fonte: própria do autor

No Quadro 1, encontram-se dados acerca de objetivos, participantes e comportamentos-alvo dos estudos com definiçóes operacionais. No Quadro 2, encontram-se os mesmos dados dos estudos sem tais definições. 
Quadro 1 - Autor, ano, objetivo, participante e base de dados na qual os artigos com definiçôes operacionais de comportamentos-alvo foram encontrados.

\begin{tabular}{|c|c|c|c|}
\hline Autor e ano & Objetivo & Participante & Base de dados \\
\hline Araújo (2007) & $\begin{array}{l}\text { Compreender como crianças cegas } \\
\text { de dois a quatro anos brincam e } \\
\text { elaboram o jogo simbólico e como } \\
\text { constróem o conhecimento acerca } \\
\text { do mundo. }\end{array}$ & $\begin{array}{l}\text { Seis participantes ( } 3 \text { meninos e } 3 \\
\text { meninas) cegos congênitos sem } \\
\text { outra deficiência associada. }\end{array}$ & Google Acadêmico \\
\hline Bigelow (1986) & $\begin{array}{l}\text { Examinar (1) qual a relação entre } \\
\text { som e toque na eliciação do alcançar } \\
\text { ou buscar objetos; (2) o que o } \\
\text { desenvolvimento do alcançar objetos } \\
\text { em crianças cegas revela sobre o } \\
\text { desenvolvimento do conceito de } \\
\text { objeto na ausência de visão. }\end{array}$ & $\begin{array}{l}\text { Cinco participantes ( } 4 \text { meninos e } 1 \\
\text { menina) nascidos totalmente cegos } \\
\text { ou com percepçáo de luz sem outra } \\
\text { deficiência associada. }\end{array}$ & Psycinfo \\
\hline Bigelow (1990) & $\begin{array}{l}\text { Estudar a relaçáo entre o desenvol- } \\
\text { vimento da permanência de objeto e } \\
\text { das primeiras palavras. }\end{array}$ & $\begin{array}{l}\text { Três participantes (meninos) cegos } \\
\text { congênitos sem outra deficiência } \\
\text { associada. }\end{array}$ & $\begin{array}{l}\text { Google Acadêmico } \\
\text { Psycinfo }\end{array}$ \\
\hline Bigelow (1992) & $\begin{array}{l}\text { Investigar a relação entre locomo- } \\
\text { ção e busca de objetos em crianças } \\
\text { cegas. }\end{array}$ & $\begin{array}{l}\text { Três participantes (meninos) } \\
\text { nascidos totalmente cegos sem outra } \\
\text { deficiência associada. }\end{array}$ & $\begin{array}{l}\text { Google Acadêmico } \\
\text { Psycinfo }\end{array}$ \\
\hline Bigelow (2003) & $\begin{array}{l}\text { Documentar a emergência de aten- } \\
\text { çáo conjunta em duas crianças cegas } \\
\text { e testar a previsão de que a atençấo } \\
\text { conjunta emerge depois que estas } \\
\text { crianças adquirem a habilidade de } \\
\text { buscar objetos. }\end{array}$ & $\begin{array}{l}\text { Dois participantes nascidos total- } \\
\text { mente cegos sem outra deficiência } \\
\text { associada. }\end{array}$ & $\begin{array}{l}\text { Google Acadêmico } \\
\text { PubMed } \\
\text { Psycinfo }\end{array}$ \\
\hline Cunha (1997) & $\begin{array}{l}\text { Verificar a eficácia de técnicas de } \\
\text { ensino naturalístico em promover } \\
\text { aquisição de linguagem funcional } \\
\text { em uma criança portadora de } \\
\text { deficiência visual com atraso de } \\
\text { linguagem. }\end{array}$ & $\begin{array}{l}\text { Uma criança cega e sua mãe (a } \\
\text { criança apresentava atrasos no } \\
\text { desenvolvimento da linguagem, } \\
\text { mas nenhuma outra deficiência foi } \\
\text { descrita). }\end{array}$ & Google Acadêmico \\
\hline Fazzi et al. (2002) & $\begin{array}{l}\text { Avaliar o desenvolvimento neuro- } \\
\text { motor de duas amostras de crianças } \\
\text { cegas congênitas ao longo dos três } \\
\text { primeiros anos de vida, dando } \\
\text { ênfase ao desenvolvimento de coor- } \\
\text { denaçáo motora grossa e do alcançar } \\
\text { objetos na presença de som. }\end{array}$ & $\begin{array}{l}\text { Trinta e sete participantes. Grupo } \\
\text { 1: } 20 \text { participantes cegos congênitos } \\
\text { sem outras deficiências associadas. } \\
\text { Grupo 2: } 17 \text { participantes cegos } \\
\text { congênitos com deficiências cogniti- } \\
\text { vas e neuromotoras associadas. }\end{array}$ & $\begin{array}{l}\text { Google Acadêmico } \\
\text { PubMed } \\
\text { Psycinfo }\end{array}$ \\
\hline Fazzi et al. (2011) & $\begin{array}{l}\text { Avaliar o desenvolvimento do } \\
\text { alcançar na presença de sons em } \\
\text { uma amostra de crianças cegas } \\
\text { congênitas. }\end{array}$ & $\begin{array}{l}\text { Trinta e sete participantes. Grupo } \\
\text { 1: } 20 \text { participantes cegos congênitos } \\
\text { sem deficiência intelectual associa- } \\
\text { da. Grupo } 2: 17 \text { participantes cegos } \\
\text { congênitos com deficiências cogniti- } \\
\text { vas e neuromotoras associadas. }\end{array}$ & Psycinfo \\
\hline $\begin{array}{l}\text { Ihsen, Troester e } \\
\text { Brambring (2010) }\end{array}$ & $\begin{array}{l}\text { Avaliar a hipótese de Fraiberg's } \\
\text { e Bigelow’s de que o alcançar na } \\
\text { presença de estímulos táteis se } \\
\text { desenvolve antes do alcançar na pre- } \\
\text { sença de (apenas) som em crianças } \\
\text { nascida cegas. }\end{array}$ & $\begin{array}{l}\text { Sete participantes cegos congênitos, } \\
\text { um com dano cerebral associado. }\end{array}$ & $\begin{array}{l}\text { Google Acadêmico } \\
\text { Psycinfo }\end{array}$ \\
\hline
\end{tabular}




\begin{tabular}{|c|c|c|c|}
\hline Medeiros (2010) & $\begin{array}{l}\text { Analisar a interação mãe-bebê com } \\
\text { deficiência visual, através da veri- } \\
\text { ficaçáo dos estilos de fala materna, } \\
\text { dos comportamentos náo verbais } \\
\text { maternos e dos comportamentos } \\
\text { comunicativos infantis. }\end{array}$ & $\begin{array}{l}\text { Doze participantes. Grupo 1: } 3 \\
\text { participantes cegos sem outra defi- } \\
\text { ciência associada e suas respectivas } \\
\text { mães. Grupo } 2: 3 \text { participantes com } \\
\text { visão e suas mães. }\end{array}$ & Google Acadêmico \\
\hline $\begin{array}{l}\text { Moore e McConachie } \\
(1994)\end{array}$ & $\begin{array}{l}\text { Investigar dois aspectos do ambiente } \\
\text { linguístico de crianças com deficiên- } \\
\text { cia visual: (1) funçấo das vocaliza- } \\
\text { çóes dirigidas às crianças cegas; }(2) \\
\text { contexto não-verbal da comunicaçâo } \\
\text { dirigida a crianças cegas. }\end{array}$ & $\begin{array}{l}\text { Dezesseis participantes. Grupo 1: } 8 \\
\text { crianças cegas; Grupo 2: } 8 \text { crianças } \\
\text { com deficiência visual severa. }\end{array}$ & Google Acadêmico \\
\hline Pérez-Pereira (1994) & $\begin{array}{l}\text { (1) Avaliar se, ao incluir o uso de } \\
\text { repetiçóes expandidas e modifica- } \\
\text { das na análise da fala das crianças, } \\
\text { gerariam-se resultados diferentes da- } \\
\text { queles de Tager-Flusberg \& Calkins } \\
\text { (1990); e (2) investigar se o uso de } \\
\text { imitaçôes, repetiçóes e rotinas aju- } \\
\text { dam a criança a analisar a linguagem } \\
\text { e a construir regras linguísticas. }\end{array}$ & $\begin{array}{l}\text { Duas irmâs gêmeas, uma cega e uma } \\
\text { com visão. }\end{array}$ & Google Acadêmico \\
\hline Peters (1987) & $\begin{array}{l}\text { Investigar os efeitos da imitação na } \\
\text { formulação de hipóteses e revisão } \\
\text { durante a aquisição de linguagem. }\end{array}$ & $\begin{array}{l}\text { Uma criança cega, entre } 18 \text { e } 40 \\
\text { meses. }\end{array}$ & Google Acadêmico \\
\hline $\begin{array}{l}\text { Sousa, Bosa e Hugo } \\
(2006)\end{array}$ & $\begin{array}{l}\text { Examinar possíveis condutas do es- } \\
\text { pectro do autismo em crianças com } \\
\text { deficiência visual congênita, quando } \\
\text { comparadas a crianças com desen- } \\
\text { volvimento típico. Ainda, investigar } \\
\text { o estilo materno de interaçáo e a } \\
\text { qualidade do brinquedo simbólico } \\
\text { nos dois grupos. }\end{array}$ & $\begin{array}{l}\text { Oito díades mãe-criança, sendo } \\
\text { quatro díades com crianças com } \\
\text { deficiência visual congênita (Grupo } \\
\text { 1) e quatro díades com crianças com } \\
\text { desenvolvimento típico (Grupo 2). }\end{array}$ & Psycinfo \\
\hline $\begin{array}{l}\text { Tröster e Brambring } \\
(1993)\end{array}$ & $\begin{array}{l}\text { (1) Investigar a compensação, em } \\
\text { relação a falta de percepção visual, } \\
\text { que pode ocorrer na área de controle } \\
\text { postural, durante o primeiro ano de } \\
\text { vida de crianças cegas; e (2) compa- } \\
\text { rar o nível de desenvolvimento de } \\
\text { crianças cegas e videntes. }\end{array}$ & $\begin{array}{l}\text { Sessenta e oito participantes: Grupo } \\
\text { 1: } 5 \text { crianças cegas congênitas, com } \\
9 \text { meses; Grupo } 2: 16 \text { crianças cegas } \\
\text { congênitas, com } 12 \text { meses; Grupo } 3 \text { : } \\
23 \text { crianças videntes com } 9 \text { meses; } \\
\text { Grupo 4: } 24 \text { crianças videntes, com } \\
12 \text { meses. }\end{array}$ & Psycinfo \\
\hline
\end{tabular}

Fonte: própria do autor 
Quadro 2 - Autor, ano, objetivo, participante e base de dados na qual os artigos sem definiçôes operacionais de comportamentos-alvo foram encontrados.

\begin{tabular}{|c|c|c|c|}
\hline Autor e ano & Objetivos & Participantes & Base de dados \\
\hline Bigelow (1987) & $\begin{array}{l}\text { Comparar a porcentagem de palavras } \\
\text { iniciais em cada categoria gramatical } \\
\text { de Nelson em crianças cegas àquela das } \\
\text { crianças videntes do estudo de Nelson. }\end{array}$ & $\begin{array}{l}\text { Três participantes (meninos) } \\
\text { nascidos cegos sem outra deficiência } \\
\text { associada. }\end{array}$ & $\begin{array}{l}\text { Google Acadêmico } \\
\text { PubMed } \\
\text { Psycinfo }\end{array}$ \\
\hline Campbell (2003) & $\begin{array}{l}\text { Comparar a interação entre mães e suas } \\
\text { crianças cegas } v \text { s. mães e suas crianças } \\
\text { videntes em atividades lúdicas. }\end{array}$ & $\begin{array}{l}\text { Oito participantes. Grupo 1: } 4 \text { par- } \\
\text { ticipantes ( } 2 \text { meninos e } 2 \text { meninas) } \\
\text { totalmente cegos, sem percepção de } \\
\text { luz e sem outra deficiência associada } \\
\text { e suas mães. Grupo } 2: 4 \text { partici- } \\
\text { pantes com visão ( } 2 \text { meninos e } 2 \\
\text { meninas) e suas mães. }\end{array}$ & Google Acadêmico \\
\hline McConachie (1990) & $\begin{array}{l}\text { Examinar: (1) os padrôes de desenvolvi- } \\
\text { mento de linguagem no segundo ano de } \\
\text { vida de crianças cegas; e ( } 2 \text { ) os efeitos } \\
\text { futuros de tais padróes. }\end{array}$ & $\begin{array}{l}\text { Oitenta e cinco participantes cegos } \\
\text { sem outra deficiência associada. }\end{array}$ & PubMed \\
\hline $\begin{array}{l}\text { McConachie e } \\
\text { Moore (1994) }\end{array}$ & $\begin{array}{l}\text { (1) Descrever o desenvolvimento de } \\
\text { linguagem expressiva infantil em uma } \\
\text { amostra representativa de crianças cegas } \\
\text { e de crianças com deficiência visual } \\
\text { severa; e (2) explorar algumas conclu- } \\
\text { sóes contraditórias que se encontram } \\
\text { descritas na literatura. }\end{array}$ & $\begin{array}{l}\text { Dezoito participantes cegos, } \\
\text { divididos em dois grupos: Grupo 1: } \\
9 \text { crianças cegas congênitas; Grupo } \\
\text { 2: } 9 \text { crianças com deficiência visual } \\
\text { severa. }\end{array}$ & $\begin{array}{l}\text { PubMed } \\
\text { Psycinfo }\end{array}$ \\
\hline
\end{tabular}

Fonte: própria do autor

Dentre os estudos que apresentaram definições operacionais, Bigelow (1986, 1990, 1992), Fazzi et al. (2002), Fazzi et al. (2011), Ihsen, Tröester e Brambring (2010), e Tröester e Brambring (1993) tiveram como foco comportamentos de buscar e/ou alcançar objetos. Mais especificamente, Bigelow (1986) examinou as possíveis relaçóes entre som e toque na eliciação do alcançar e do buscar objetos ao apresentar a seus participantes diversas condições experimentais envolvendo estímulos sonoros ou táteis. Bigelow (1990) estudou a relação entre o desenvolvimento da permanência de objeto e a emissáo de primeiras palavras a partir da análise do alcançar e do buscar objetos e sua correlação com as primeiras 50 palavras emitidas pelos participantes, levando em conta o contexto no qual tais palavras foram emitidas. Bigelow (1992) investigou a relação entre locomoção e busca de objetos em crianças cegas tendo como foco os comportamentos de engatinhar, andar e buscar objetos na presença de estímulos sonoros e na presença de estímulos táteis.

Fazzi et al. (2002) avaliaram o desenvolvimento neuromotor de duas amostras de crianças cegas congênitas ao longo dos três primeiros anos de vida, dando ênfase ao desenvolvimento de coordenação motora grossa (por exemplo, controle de cabeça, sentar sem suporte e ficar em pé) e do alcançar objetos na presença de estímulos sonoros. Fazzi et al. (2011) focaram suas observaçóes apenas no desenvolvimento do alcançar na presença de 
estímulos sonoros. Ihsen, Tröester e Brambring (2010) testaram a hipótese de que o alcançar na presença de estímulos tácteis se desenvolve antes do alcançar na presença de (apenas) som em crianças nascidas cegas. Para tanto, avaliaram o comportamento de alcançar objetos silenciosos e objetos produtores de som quando estes estavam em contato com o corpo da criança ao longo de toda a tentativa; quando os objetos estavam em contato com o corpo da criança apenas no início da tentativa e quando os objetos não entravam em contato com o corpo da criança. Finalmente, Tröster e Brambring (1993) compararam o nível de desenvolvimento motor de habilidades diretamente ligadas à coordenação viso-motora (coordenação motora fina e desenvolvimento locomotor) e o nível de desenvolvimento de habilidades não diretamente ligadas à visão (controle postural em pronação, em postura supino, durante o sentar e durante o ficar em pé) de crianças cegas àquele de crianças videntes. Para tanto, observaram diversos comportamentos como reações de orientação, controle postural e habilidades manuais básicas, coordenação locomotora e coordenação motora fina.

Ainda dentre os estudos que apresentaram definiçôes operacionais, Bigelow (2003) procurou documentar a emergência de atenção conjunta em duas crianças cegas e testou a previsão de que a atenção conjunta emerge depois que as crianças adquirem a habilidade de buscar objetos. Seu foco foi em duas categorias de comportamentos de atenção conjunta. A primeira categoria, chamada comportamentos liberalmente denominados atenção conjunta, incluía análises acerca da criança usar instruçóes dadas por um adulto para encontrar e manipular objetos. A segunda categoria, comportamentos denominados atenção conjunta de forma conservadora, incluía a análise se a criança repetidamente oferecia um objeto a um adulto e o pegava de volta, usando o objeto como ferramenta para a interação.

Finalmente, ainda dentre os estudos que apresentavam definiçóes operacionais, diversos documentaram o desenvolvimento das primeiras palavras e outras interaçóes comunicativas entre mães e seus bebês cegos. Cunha (2007) verificou a eficácia de técnicas de ensino naturalístico na promoção de aquisição de linguagem funcional em uma criança portadora de deficiência visual com atraso de linguagem, analisando comportamentos linguísticos da mãe (dicas para a criança verbalizar - estímulos antecedentes e respostas verbais - estímulos consequentes) e comportamentos linguísticos da criança divididos também em duas categorias (respostas obrigatórias - após dica para verbalizar e respostas espontâneas - sem dicas). Moore e McConachie (1994) investigaram aspectos do ambiente linguístico de crianças cegas e de crianças com deficiência visual severa tendo seu foco na iniciação e manutenção de interaçóes verbais. Pérez-Pereira (1994) avaliou se, ao incluir o uso de repetiçóes expandidas e modificadas na análise da fala das crianças, resultados diferentes daqueles de Tager-Flusberg e Calkins (1990) seriam encontrados. As imitaçóes, repetiçóes e rotinas de fala foram analisadas em três dimensões: tipo, fidelidade ao modelo e função. Peters (1987) investigou os efeitos da imitação na formulação de hipóteses e revisão (análise) do uso da linguagem durante sua aquisição. Suas análises incluíram a emergência do uso correto de pronomes e o desenvolvimento do uso de perguntas abertas (quem, quando, onde). Araújo (2007) buscou compreender o jogo simbólico de crianças cegas, avaliando a complexidade de tais interaçôes entre a criança e objetos. Medeiros (2010) comparou a interação mãe-bebê de crianças cegas e de crianças videntes através da verificação dos estilos de fala materna, dos comportamentos não verbais maternos e dos comportamentos comunicativos infantis. A autora analisou diversas categorias 
de comportamentos-alvo incluindo comportamentos comunicativos verbais da mãe (por exemplo, estilos de fala materna, como requisiçóes, comentário, feedback); comportamentos não verbais maternos dirigidos (contato físico, gestos, observação, demonstração de afeto e atividades de cuidado) e episódios de atençáo conjunta.

Dentre os estudos sem definição operacional, Bigelow (1987) comparou a porcentagem das 50 primeiras palavras em cada categoria gramatical de Nelson (1973) em crianças cegas àquela das crianças videntes participantes de tal estudo. McConachie (1990) examinou os padróes de desenvolvimento de linguagem no segundo ano de vida de crianças cegas e como tais padróes poderiam afetar o desenvolvimento futuro de tais crianças. Para tanto, analisou comportamentos ligados à compreensão verbal (por exemplo, reconhecimento de sons e palavras familiares) e de estrutura de linguagem expressiva (emissão de palavras definidas e reconhecidas como tal pela comunidade verbal). McConachie e Moore (1994) descreveram o desenvolvimento de linguagem expressiva infantil analisando as primeiras palavras das crianças e o contexto nas quais foram emitidas. Finalmente, Campbell (2003) comparou a interação entre mães e suas crianças cegas com a interação de mães de crianças videntes em diversas atividades de brincar livre.

\section{Conclusāo}

A partir das palavras-chaves e critérios utilizados na presente revisão bibliográfica, foram encontrados 19 estudos, os quais estão, em sua maioria, publicados em periódicos internacionais, entre esses, apenas dois estão publicados em periódicos brasileiros. Os resultados apontam a necessidade de mais estudos serem conduzidos e/ou publicados nacionalmente: publicaçóes em outras línguas provavelmente não são acessíveis para a maior parte dos profissionais brasileiros e um maior número de publicaçóes nacionais forneceria mais suportes para aqueles leitores interessados nesta área.

Ainda em relação à publicação dos estudos, estes foram encontrados em 11 periódicos diferentes. Esta diversidade de periódicos pode dificultar a busca e o acesso aos leitores. Dados os resultados obtidos no presente estudo, talvez a melhor estratégia para a busca de estudos na área seja, 1) iniciar pela base de dados Google Acadêmico e 2) realizar buscas em outras bases de dados antes de buscar periódicos específicos.

Em relação aos comportamentos-alvo utilizados como palavras-chave, estes foram cunhados a partir de categorias presentes em escalas de avaliação de comportamentos linguísticos. Isto torna tais comportamentos prováveis de fazerem parte do repertório comportamental que deve ser avaliado para detecçáo de atrasos do desenvolvimento da linguagem. Os artigos encontrados, especialmente aqueles com definiçóes operacionais, podem fornecer ferramentas importantes para a avaliação fidedigna e confiável de tais comportamentos. Desta forma, intervençôes baseadas nestas avaliaçóes provavelmente serão mais efetivas e objetivamente direcionadas a déficits que precisam ser remediados. Os objetivos dos estudos encontrados também podem ser utilizados como forma de localizar avaliaçóes que sejam efetivas.

Outro ponto que merece destaque é o fato de que os estudos relacionados à emissão de primeiras palavras e a outras interaçóes comunicativas foram aqueles que mais utilizaram 
o contexto no qual os comportamentos foram emitidos como forma de avaliar estes (vide resultados). A importância da utilização do contexto precisa ser ressaltada quando se analisam comportamentos linguísticos, pois é o contexto que fornece informaçóes acerca de eventos antecedentes e consequentes, os quais determinam a função dos comportamentos linguísticos. Além disso, conforme ressaltado por Andersen et al. (1993), a aquisição de linguagem não acontece na ausência de contexto e, portanto, faz-se necessário considerá-los durante avaliaçóes e intervençóes relacionadas a comportamentos linguísticos.

Outra questão que merece ser ressaltada diz respeito à definição operacional dos comportamentos-alvo. No presente estudo foi categorizada apenas a presença ou a ausência de definição operacional destes comportamentos. Estudos futuros devem investigar esta questão mais a fundo, hierarquizando as definiçóes operacionais de acordo com a sua completude, baseando-se especialmente na descrição de eventos antecedentes e consequentes, os quais estabelecem o contexto de emissão de comportamentos linguísticos. Esta análise pode auxiliar o leitor que busca definições mais objetivas e completas a construir avaliaçóes e intervençôes mais robustas, pois conforme ressaltado por Lin e Kubina (2004), “seja no laboratório ou na prática, definições precisas facilitam medir, observar, replicar e analisar...” (p. 5) comportamentos-alvo.

Os resultados encontrados apontam para a dificuldade em localizar estudos sobre a temática, assim como para a grande variedade de periódicos em que estão agrupados, o que aumenta ainda mais a dificuldade de localização e acesso dos mesmos. Desta forma, ao realizar a presente revisão, procurou-se fornecer ferramentas ao leitor que busca avaliaçóes e intervençóes efetivas que tenham sido já utilizadas com crianças cegas congênitas com risco de atrasos no desenvolvimento da linguagem. $\mathrm{O}$ presente artigo sintetisa diversos estudos que abordam o desenvolvimento da linguagem em crianças cegas congênitas e pode ser utilizado como um guia para pesquisas futuras na área.

\section{REFERÊNCIAS}

ANDERSEN, E.S.; DUNLEA, A.; KEKELIS, L. The impact of input: language acquisition in the visually impaired. First Language, Thousand Oaks, v. 12, n. 1, p. 23-49, 1993.

. Blind children's language: Resolving some differences. Journal of Child Language, Cambridge, v. 11, n. 3, p. 645-664, 1984.

ARAÚJO, S.C. O jogo simbólico da criança cega. 2007. 146f. Dissertação (Mestrado em Educação) Faculdade de Educação, Universidade Federal da Bahia, Salvador, 2007.

BANDINI, C.S.M. A geratividade do comportamento verbal: divergências entre as propostas de B. F. Skinner e N. Chomsky. 2008. 239f. Tese (Doutorado em Filosofia) - Pós-graduação em Filosofia, Universidade Federal de São Carlos, São Carlos, 2008.

BIGELOW, A.E. The development of reaching in blind children. British Journal of Developmental Psychology, London, v.4, n.4, p.355-366, 1986.

1987.

. Early Words of blind children. Journal of Child Language, Cambridge, v.14, n.1, p 47-56,

. Relationship between the development of language and thought in young blind children.

Journal of Visual Impairment \& Blindness, Baltimore, v.84, n.8, p. 414-419, 1990. 
. Locomotion and search behavior in blind infants. Infant Behavior and Development, New York, v.15, n.2, p.179-189, 1992.

. The development of joint attention in blind infants. Development and Psychopathology, Cambridge, v.15, n.2, p.259-275, 2003.

BLOOMBERG, K.; WEST, D. The Triple C: Checklist of Communication Competencies. Communication Resource Centre: Victoria, 1999.

BOUDREAU, D.M.; HEDBERG, N.L. A comparison of early literacy skills in children with specific language impairment and their typically developing peers. American Journal of Speech and Language Pathology, Rockville, v.8, n.3, p.249-260, 1999.

BUSCHMANN, A. et al. Parent based language intervention for 2-year-old children with specific expressive language delay: a randomized controlled trial. Archives of Disease in Childhood, London, v.94, n.2, p.110-116, 2009.

CAMPBELL, J. Maternal directives to young children who are blind. Journal of Visual Impairment \& Blindness, Baltimore, v.97, n.6, p. 355-365, 2003.

CUNHA, A.C.B. Promovendo aquisição de linguagem funcional em criança deficiente visual: o efeito de um treinamento de mãe em procedimentos de ensino naturalístico. Temas em Psicologia, Ribeirão Preto, v. 5, n. 2, p.33-56, 1997.

FAZZI, E. et al. Gross motor development and reach on sound as critical tools for the development of the blind child. Brain and Development, Maryland Heights, v.24, n.5, p.269-275, 2002.

FAZZI, E. et al. Reach on sound: A key to object permanence in visually impaired children. Early Human Development, Maryland Heights, v.87, n.4, p.289-296, 2011.

FRAIBERG, S. Intervention in infancy: A program for blind infants. Journal of the American Academy of Child Psychiatry, Maryland Heights, v. 10, p. 381-405, 1971.

FRAIBERG, S. Insights from the blind: comparative studies of blind and sighted infants. 1.ed. New York: Basic Books, 1977.

FUJIKI, M.; BRINTON, B.; TODD, C.M. Social skills of children with specific language impairment. Language, Speech, and Hearing Services in Schools, Rockville, v. 27, n. 3, p. 195-202, 1996.

GILLAM, R.B. et al. The efficacy of fast forward language intervention in school-age children with language impairment: a randomized controlled trial. Journal of Speech, Language, and Hearing Research, Rockville, v. 51, n. 1, p. 97-119, 2008.

IHSEN, E.; TROESTER, H.; BRAMBRING, M. The role of sound in encouraging infants with congenital blindness to reach for objects. Journal of Visual Impairment \& Blindness, Baltimore, v.104, n. 8, p. 478-488, 2010.

IVERSON, J.M. et al. The relation between gesture and speech in congenitally blind and sighted language-learners. Journal of Nonverbal Behavior, Riverside, v. 24, n. 2, p. 105-130, 2000.

LIN, F.; KUBINA JR., R. Learning Channels and Verbal Behavior. The Behavior Analyst Today, v. 5, n. 1, p. 1-14, 2004.

< http://www.baojournal.com/BAT\%20Journal/VOL-5/BAT-5-1.pdf>. Acesso em: 12 jun. 2012.

MCCONACHIE, H. Early language development and severe visual impairment. Child: Care, Health and Development, Oxford, v. 16, n. 1, p. 55-61, 1990. 
MCCONACHIE, H.R.; MOORE, V. Early expressive language of severely visually impaired children. Developmental Medicine \& Child Neurology, London, v. 36, n. 3, p. 230-240, 1994.

MEDEIROS, C.S. Estilos comunicativos e interação mãe-bebê com deficiência visual. 2010. 165f. Dissertação (Mestrado em Psicologia Social) - Departamento de Pós-Graduação em Psicologia Social, Universidade Federal da Paraíba, João Pessoa, 2010.

MILLS, A.E. Language acquisition and development with sensory impairment: Blind children. In: BLANKEN, G.; DITTMANN, J.; GRIMM, H.; MARSHALL, J.C.; WALLESCH, C.W. (Eds.), Linguistic disorders and pathologies: An international handbook. Berlim: Walter de Gruyer, 1993. p. 679-687.

MOORE, V.; MCCONACHIE, H.R. Communication between blind and severely visually impaired children and their parents. British Journal of Developmental Psychology, Leicester, v. 12, n. 4, p. 491502, 1994.

NELSON, K. Structure and strategy in learning to talk. Monographs of the Society for Research in Child Development, Ann Harbor, v. 38, n. 149, p. 1-135, 1973.

ROWLAND, C. Online Communication Matrix. Disponível em: <http://www.communicationmatrix. org/>. Acesso em: 20 set. 2009.

PÉREZ-PEREIRA, M. Imitations, repetitions, routines, and the child's analysis of language: insights from the blind. Journal of Child Language, Cambridge, v. 21, n. 2, p. 317-337, 1994.

PETERS, A.M. The role of imitation in the developing syntax of a blind child. Text - Interdisciplinary Journal for the Study of Discourse, Berlin, v. 7, n. 30, p. 289-309, 1987.

PREISLER, G. Early patterns of interaction between blind infants and their sighted mothers. Child: care, health and development, Oxford, v. 17, n. 1, p. 65-90, 1991.

QI, C.H.; KAISER, A.P. Problem behaviors of low-income children with language delays: An observation study. Journal of Speech, Language, and Hearing Research, Rockville, v. 47, n. 3, p. 595-609, 2004.

SILVER, M.A. Speech and language assessment. In: GOODMAN, S. A.; WITTENSTEIN, S.H. (Eds.). Collaborative assessment: Working with students who are blind or visually impaired, including those with additional disabilities. American Foundation for the Blind: New York, 2003. Cap. 7, p. 196-236.

SKINNER, B.F. Verbal Behavior. 2. ed. Cambridge: Prentice Hall, 1992.

SOUSA, A.D.; BOSA, C.A.; HUGO, C.N. As relaçôes entre deficiência visual congênita, condutas do espectro do autismo e estilo materno de interação. Estudos de Psicologia, Campinas, v. 22, n. 4, p. 355-364, 2006.

SUNDBERG, M.L. Verbal behavior. In: COOPER, J.O.; HERON, T.E.; HEWARD, W.L. Applied behavior analysis. 2. ed., Upper Saddle River: Merrill/Prentice Hall, 2007. Cap. 25, p. 526-547.

TAGER-FLUSBERG, H.; CALKINS, S. Does imitation facilitate the acquisition of grammar? Evidence from a study of autistic, Down syndrome and normal children. Journal of Child Language, Cambridge, v. 17, n. 13, p. 591-606, 1990.

TRÖSTER, H.; BRAMBRING, M. Early motor development in blind infants. Journal of Applied Developmental Psychology, Norwood, v. 14, n. 1, p. 83-106, 1993. 
URWIN, C. Preverbal communication and early language development in blind children. Papers and reports on child language development, Stanford, v. 17, n. 1, p. 119-127, 1979.

WARREN, S.F.; FEY, M.E.; YODER, P.J. Differential treatment intensity research: a missing link to creating optimally effective communication interventions. Mental Retardation and Developmental Disabilities Research Reviews, Malden, v. 13, n. 1, p. 70-77, 2007.

Recebido em: 05/10/2012

Reformulado em: 19/05/2013

Aprovado em: 22/05/2013 
SELLA, A.C.; CHIODELLI, T.; MENDES, C.A. 